\title{
El grabado, una producción híbrida como problema para el relato modernista
}

\author{
Silvia Dolinko*
}

\begin{abstract}
Resumen:
Este trabajo revisa algunos de los abordajes canónicos respecto del estatuto del grabado como producción artística, tanto desde el factor de la técnica gráfica como desde su recurrencia a la narratividad o a la figuración, vinculada muchas veces con el universo de la ilustración literaria o a la puesta en circulación de discursos sociales e imágenes de contenido político "militante". Se formula como hipótesis que tanto la narratividad como la multiplicidad del grabado han resultado un problema en relación con el canon modernista; se sostiene que la condición figurativa -de ilustración y/o social- del paradigma gráfico situó al grabado como una de las producciones excluidas del relato del modernismo, a la vez que la reclusión de los grabadores en el virtuosismo técnico como parámetro de validación implicó una autoexclusión del mismo.
\end{abstract}

\section{Palabras clave:}

Grabado, técnica, obra múltiple, figuración, relato modernista.

\section{1.}

A lo largo del siglo $\mathrm{XX}$, el grabado asistió a una progresiva autonomización $\mathrm{y}$ valorización como disciplina artística. Si distintos factores -ampliación de recursos formales, renovación de técnicas, una nueva consideración por parte del mercado de arte, etc.- confluyeron en la construcción y consolidación de esta obra múltiple como una producción relevante dentro del mapa de la producción simbólica, alejada de sus orígenes reproductivos, también persistieron diversos tópicos respecto de cómo entenderla o categorizarla.

Xilografías, aguafuertes, litografías, entre otras modalidades convencionales del grabado, implican una producción estampada a partir de una matriz, impresa en soporte de papel, editada en una serie o como pruebas de artista que dan cuenta de los diferentes estadios del desarrollo de la imagen. Un abordaje canónico sobre el estatuto artístico del grabado parte de la pregunta por la técnica. Una técnica que no implica una reflexión en torno a la relación de uso y dominio en sentido heideggeriano, ni una consideración sobre la transformación del repertorio de formas e instrumentos materiales del arte a partir del impacto de nuevas máquinas y tecnologías como observara Pierre Francastel, sino la técnica como el cuestionamiento por el hacer, por el rol del oficio. Ese sentido sostenido por Paul Valéry al dirigirse a los peintres-graveurs, categoría que otorgaba un

* Doctora en Historia del Arte por la Universidad de Buenos Aires 
viso de prestigio a los artistas que exploraban las posibilidades gráficas. ${ }^{1}$ Valéry -una de las "voces de autoridad" en la reflexión de Walter Benjamin en torno a la reproductibilidad artística en la modernidad- indagaba sobre la "conquista de la ubicuidad", ${ }^{2}$ a la vez que enfatizaba en un texto de principios de los años treinta sobre la producción del grabador desde el punto de vista del beau métier artesanal:

el hombre actúa; ejerce sus fuerzas sobre una materia ajena, distingue sus actos de su soporte material, y tiene de ellos conciencia clara; de ese modo los puede concebir y combinar antes de ejecutarlos, darles las aplicaciones más variadas y ajustarlos a las sustancias más diversas, $y$ a ese poder de componer sus empresas o descomponer sus designios en actos distintos es a lo que llama inteligencia. No se confunde con la materia de su obrar, sino que va y viene de ella a su idea, de su espíritu a su modelo, y a cada momento troca lo que quiere por lo que puede, $y$ lo que puede por lo que obtiene. ${ }^{3}$

¿Qué hay de particular o convocante en la praxis gráfica para que este esquema explicativo se mantuviera durante décadas para justificar su especificidad? ${ }^{4}$ Existen algunas características técnicas y simbólicas que se han sostenido con fuerza desde el campo específico de la gráfica y que ejemplifican las ambigüedades que operan en el abordaje de esta producción. Se trata de una "obra bisagra", intermediaria entre la creación única y prestigiada desde el circuito tradicional y el arte reproducible por medios industriales y de consumo masivo. La problemática del grabado en el cruce entre la obra única y la múltiple o, más exactamente, entre la producción de escala restringida y escala masiva, da cuenta de su condición híbrida.

En efecto, una de las características básicas para la conformación del "concepto grabado" parte de la idea de multiejemplaridad; sin embargo, desde su estatuto de obra múltiple, se ponen en juego una serie de paradojas. Por ejemplo, si su especificidad posibilita la reproductibilidad y pluralidad en la circulación de imágenes, a lo largo del siglo XX se articuló la idea de la estampa como un "original múltiple", avanzándose desde los años sesenta hacia los grabados únicos, es decir, sin formar parte de una tirada o conjunto de pruebas de artista.

Si la multiplicidad es una de las particularidades del grabado, los límites de la obra múltiple evidencian otras paradojas de esta disciplina. Por ejemplo, su asociación a la idea de una producción cultural ampliada en su circulación social,

1 Una referencia clásica es la edición de Adam Bartsch, Le Peintre-graveur, 21 vol., Viena, 18031821.

2 Texto publicado originalmente en De la musique avant toute chose, Editions du Támbourinaire, 1928 y reproducido en Nouvelles Littéraires el 28 de marzo de 1931.

3 "Pequeño discurso a los pintores grabadores" (En Piezas sobre arte, p. 147. El destacado es del original). Se trata de un discurso pronunciado el 29 de noviembre de 1933 en la cena de Pintores Grabadores franceses.

4 Por citar un ejemplo cercano, en la sala de estampas del Museo Nacional de Bellas Artes de Buenos Aires, inaugurada hace pocos años, se adosa en la pared una explicación sobre las técnicas del grabado, esquema que no se aplica a otras áreas del mismo recorrido museográfico. 
que tendría que posibilitar una potenciación de espectadores o consumidores; sin embargo, se puede entender que el grabado en realidad resulta extraño para el gran público. Obra múltiple pero casi desconocida, obra múltiple pero individual: diferentes lugares incómodos para el grabado. Incómodos o paratópicos, en el sentido sostenido por Dominique Maingueneau (1995) respecto de una ubicación paradójica, una posición imposibilitada de establecerse, sin terminar de definir o encontrar un lugar propio. El grabado como descentrado de un lugar en el campo artístico que nunca acaba de definirse del todo, porque aparece desplazado: de la centralidad de los dispositivos expositivos, de la valoración hegemónica, de los relatos canónicos. O, también, auto desplazado por los propios artistas gráficos que en muchas ocasiones se han atrincherado en el mantenimiento de un "coto cerrado" técnico.

En este sentido, dentro de las particularidades que se han sostenido en la práctica tradicional del quehacer gráfico se destaca el factor de la artesanalidad, esto es, la tradición ligada al beau métier como elemento constitutivo para la valoración del grabado canónico y que también hasta los años sesenta, especialmente con la novedosa gráfica conceptualista, no fue puesto en cuestión. Esta valoración no se restringió específicamente al "objeto-estampa", sino que se aplicó también a la matriz, con la restricción a la imagen negativa realizada sobre el soporte en tanto base para la edición.

Toda esta reglamentación que debía funcionar de forma implícita en la praxis fue enunciada en diversas ocasiones a través de textos técnicos que operaron a modo de manual de instrucciones para el neófito o el artista poco entrenado. La realización de las tareas gráficas efectuadas con minuciosidad, muchas veces con gran énfasis en el virtuosismo técnico, la limpieza del trazo y la meticulosidad en el manejo de los materiales y de los elementos compositivos se vinculaba al savoir faire del profesional como condición básica para este tipo de producción. El énfasis en la "presencia" del artista a partir de su acción sobre la materia, de la impronta de su trabajo en la matriz y en el proceso de la impresión constituirían distintos estadios que finalmente posibilitarían intuir "una especie de intimidad estrecha entre la obra que se forma y el artista que a ella se aplica". (Valery, 145).

Marcas de la materia -como los rastros de la tinta de impresión, el sutil modulado del papel por la presión de la prensa, el contorno rehundido del límite de la matriz- aportan un registro material para la constatación de la "autenticidad" de la estampa. ${ }^{5}$ En el caso de la imagen xilográfica, por ejemplo, se pone en un primer plano la imbricación del trabajo manual del artista, la carga sensible del material y su remisión a lo orgánico desde las texturas de la madera, sus vetas y nudos. La pregunta por "la huella creadora, desde la impresión real hasta la firma" permite sostener a Jean Baudrillard que "la fascinación del objeto artesanal le viene de que pasó por la mano de alguien cuyo trabajo está todavía inscrito en

5 Estoy refiriendo a las técnicas más tradicionales del grabado que serán ampliadas o puestas en cuestión a partir de los años sesenta, con la incorporación de nuevas modalidades de impresión y la redefinición del médium. 
él: es la fascinación de lo que ha sido creado y que por eso es único, puesto que el momento de la creación es irreversible" (Baudrillard, 1995, p. 87); sin embargo, en el caso del grabado, su potencial multiejemplaridad complejiza esta lectura, ya que no resulta ni una obra única ni una producción de masas, sino un producto intermedio o, como se ha mencionado, híbrido.

La artesanalidad de la obra múltiple y la acción simbólica de la reiteración de la imagen fue aludida por Francis Ponge cuando describió, a través de una "personalización" de la memoria de la piedra litográfica, el gesto de repetir las imágenes como un ritual: "exactement comme une personne maniaque accomplit ses rites subrepticement, pour elle seule (des gestes pour soi seul: curieux, cette extériorisation sans fin extérieure...)." (Ponge, 1977, p. 49). Se trata de reflexionar sobre el sentido de una obra repetible pero impresa artesanalmente, numerada y firmada; en este caso, la firma del autor forma parte de una marca de autenticidad -o de "autorización"- del propio creador. Mary Kelly la interpreta como "la marca autentificadora que ocupa un lugar tan preeminente en la peculiar estructura de deseo e intercambio del mercado de arte. No sólo se compra una obra de arte en concreto (el título), sino también 'algo' que sólo posee un individuo (el nombre). La garantía de ese 'algo', que consiste en que un objeto aparezca investido de subjetividad artística, es un gesto, o más explícitamente, una firma." (Kelly, 2001, p. 90).

A la vez, la estampa o la serie lleva un registro que también forma parte del código específico de la disciplina: la numeración de la tirada que opera como control de la secuencia de impresiones. Y si bien, en términos generales, estas estrategias han resultado operativas al mercado de arte, también fueron un recurso aceptado para ediciones con finalidades sociales o militantes. ${ }^{6}$ La numeración presenta entonces una dicotomía de base: implica otorgar un registro individual a una obra para señalar su inclusión en una serie múltiple. Es decir, a partir de la numeración cronológica, se otorga a cada estampa un registro de cierta unicidad y a la vez se la incluye dentro de una secuencia: nuevamente, la tensión entre lo único y lo múltiple. ¿Podemos interpretar que a través de esta operación de la numeración se intenta recuperar algo del aura atribuido a la obra única?

\section{2.}

De forma casi tan recurrente como sucede con la apelación al glosario técnico, la conceptualización sostenida por Walter Benjamin acerca de la reproductibilidad de la obra de arte constituye otro punto explicativo en diversos abordajes sobre esta producción. Entre sus lecturas acerca de los cambios en las condiciones de producción en el campo de la cultura de la modernidad, y de las relaciones entre devenir técnico y forma estética como matriz para pensar la relación entre arte y

6 Por ejemplo, el caso de Vaincre, álbum colectivo y clandestino de doce litografías que, propiciado por André Fougeron y realizado por artistas próximos al Partido Comunista Francés, fue vendido a beneficio de los FTP en abril de 1944. (Cf. Laurence Bertrand Dorléac. L'art de la défaite,1940-1944. Paris : Editions du Seuil, 1993). A pesar de tratarse de una producción de circulación clandestina, las 300 estampas que conformaban la tirada fueron numeradas: se mantenía así un criterio de control y secuenciación sostenido desde el sistema comercial más convencional.. 
sociedad, la indagación sobre los efectos de la reproductibilidad de la obra de arte y la consecuente pérdida del aura - "un espinoso y polimorfo valor de uso", como lo ha definido Georges Didi-Huberman (1997, p. 93)- constituye uno de los ejes más transitados por la bibliografía crítica sobre la cuestión.

Inscripta en el marco más general de su Passagen-Werk, es bien sabido que Benjamin reflexiona en "La obra de arte en la época de su reproductibilidad técnica"7 sobre los cambios históricos y las transformaciones de la sensibilidad moderna, desarrollando in extenso su noción de aura y su declive o pérdida en la obra de arte reproducible. En esos tiempos en que Benjamin mantenía una posición optimista respecto de la promesa de la tecnología como vía para la democratización de la producción y recepción artística, apuntaba a indagar, en definitiva, sobre los modos en los que la conformación y transmisión de la cultura constituyen una forma de acto político. En este sentido, las técnicas de reproducción ponían en cuestión la tradición cultural burguesa, estableciendo una nueva vinculación entre la técnica artística y el movimiento político de masas.

Ahora bien, si las referencias a Benjamin aparecen de forma reiterada en los estudios sobre la obra gráfica, cabe preguntarse ¿cuál es efectivamente el lugar o la significación de esta producción en la reflexión benjaminiana sobre la obra de arte reproducible? El autor reconoce que desde la antigüedad se asistió a las exploraciones sobre la reproducción técnica de la obra de arte, "algo nuevo que se impone en la historia intermitentemente, a empellones muy distantes unos de otros, pero con intensidad creciente" (pp. 18-19). En este sentido, los grabados - la xilografía medieval o la litografía decimonónica- configuran en su genealogía un estadio intermedio, situado entre los bronces antiguos y la aparición de la fotografía en tanto "antesala" o "prehistoria" de las nuevas prácticas perceptivas. Aunque estima que la xilografía "hizo que por primera vez se reprodujese técnicamente el dibujo, mucho tiempo antes de que por medio de la imprenta se hiciese lo mismo con la escritura" (p. 19) y en el Passagen-Werk entiende a la litografía como "técnica de reproducción", 8 la gráfica no constituye para Benjamin más que un antecedente frente al poder multiplicador del cine, ejemplo central de su argumentación sobre la reproductibilidad técnica.

Es decir, el grabado implica copias múltiples, idénticas y reproducibles; sin embargo, no se encuentra reproducido industrialmente, y no constituye estrictamente un "arte de masas", factores que apuntan a sostener la idea de su estatuto híbrido. Esta condición lo acerca en mayor medida a la carga individual de la obra única que permite la supervivencia de la distancia aurática, ya que aunque esta obra multiejemplar posibilita una pluralidad de poseedores, la detentación final de un ejemplar gráfico no lo convierte en "propiedad colectiva" sino que termina circunscribiéndose en el registro individual de una colección privada. Es desde

7 Para el presente estudio fue consultada la versión incluida en Discursos interrumpidos. Barcelona: Planeta, 1994, pp. 17-57.

8 Según señala Susan Buck-Morss (1995), el manuscrito de "La obra de arte..." es contemporáneo al exposé de 1935 del Passagen-Werk, su trabajo nunca concluido acerca del efecto de la producción industrial sobre las formas culturales tradicionales, donde refiere a la cultura de masas no sólo como conformadora de la sensibilidad moderna, sino también como fuente de "verdad filosófica". 
esta perspectiva que se puede pensar en cierta intimidad en la relación obracoleccionista: "el concepto de autenticidad jamás deja de tender a ser más que una adjudicación de origen. (Lo cual se pone especialmente en claro en el coleccionista, que siempre tiene algo de adorador de fetiches y que por la posesión de la obra de arte participa de su virtud cultual)" (Benjamin, p. 27). ${ }^{9}$

Planteando esta cuestión desde el estricto sentido material de la estampa, volvemos a retomar la idea de que la señalización de la obra dentro de la serie, a través de la firma y la numeración, preserva cierta noción de unicidad de la obra múltiple. Desde una postura crítica, Luis Camnitzer ha subrayado los efectos restrictivos de esta particular lectura:

La apreciación de un grabado [...] se produce a escala de la hoja impresa en sí misma, y si bien se admite la existencia de otras imágenes impresas iguales como formando parte de una edición, éstas no tienen influencia entre sí. La apreciación también es pictoricista u 'original'. Desde la concepción del grabado hasta la recepción por parte del espectador, el criterio frente al diseño es el de unicidad. La preocupación creativa queda limitada al aspecto de ese grabado-resultado" (Camnitzer, 1969). ${ }^{10}$

Sin embargo, desde la idea de que una obra de arte múltiple conllevaría una vocación plural o "popular", el efecto simbólico del factor multiplicidad del grabado implicaría conceptualmente una desacralización de la obra única, uno de los ejes privilegiados de la validación burguesa de la obra de arte. Esto plantea otro aspecto paradójico del grabado: cabe recordar que su primera expansión en la cultura occidental se produjo como vía de difusión de imágenes en los siglos XIV-XV, momento de conformación de la idea de "arte burgués". Se puede seguir en este punto a Raymond Williams cuando plantea que con la aparición de las tecnologías de reproducción gráfica, su diversidad y movilidad, "lo que se había logrado técnica y socialmente no sólo era la ampliación de la distribución, sino también la movilidad inherente de los objetos culturales, de importancia crucial para las relaciones regulares de mercado." (Williams, 1994, p. 91). A la vez, aunque la multiplicidad apuntaría a una circulación social ampliada, algunas características materiales de la estampa -fragilidad del soporte papel, pequeño formato, minuciosidad técnica de realización- motivaron la reiterada calificación del grabado como arte de cámara. Así, por ejemplo, Aldo Pellegrini refería en 1963 que "el grabado ha adquirido en los tiempos modernos una autonomía e importancia tal que le hace representar frente a la gran pintura el papel que tiene

\footnotetext{
9 Esta relación también la analiza David Freedberg (1992, p. 40) cuando se pregunta: "¿̇respondemos de una manera más intensa -más violenta y ostensiblemente- a un cuadro colgado en un lugar público o a un pequeño grabado [...] que podemos conservar y mirar a nuestro gusto relamiéndonos con él en privado?". Para ejemplificar esta cuestión, el autor propone el caso particularmente connotado de la obra erótica de Sebald Beham. También Baudrillard, a partir de un caso mencionado por La Bruyère, ilustra "la curiosidad como pasión" a partir del ejemplo de un coleccionista de estampas. (p. 104). 
la música de cámara frente a la música sinfónica". ${ }^{11}$

Partiendo de los aspectos generales sobre el grabado planteados en este punto, es posible avanzar sobre algunas hipótesis interpretativas tanto respecto de la definición de los parámetros de selección y validación que conformaron las fronteras desde las que operó esta producción, como así también respecto de su relación problemática con el relato modernista.

\section{3.}

El lugar descentrado de la gráfica en el campo cultural del siglo XX ha sido sostenido por las lecturas canónicas que han establecido una hipótesis, o más bien, un diagnóstico sobre su posición marginal o anexa en relación con el sistema de las artes visuales -especialmente con la pintura como principal referente. Ahora bien, si se parte de la idea de que la jerarquía entre disciplinas resulta de situaciones establecidas históricamente, ¿desde qué marco interpretativo se puede abordar esta cuestión de la posición restrictiva del grabado? ¿Cuál es el grado de incidencia de los relatos hegemónicos en el posicionamiento de esta producción? ¿Cuáles fueron los discursos o las estrategias de los grabadores?

Evidentemente, la estratificación entre disciplinas a partir de un canon divisorio entre "artes mayores" y "artes menores" establecido desde la temprana modernidad ${ }^{12}$ resultó sistemáticamente revisado y atacado por los artistas a lo largo del siglo XX. Sin embargo, implícita o muchas veces explícitamente, la dinámica del campo artístico ha mantenido una latente jerarquización que, en lo que se refiere al grabado, lo situó en un plano menos significativo o casi excluido respecto de otras disciplinas. Por su parte, los "grabadores esenciales" establecieron una especie de autoexclusión que demarcaba la validación de su producción desde un marco propio y diferencial. Es este doble movimiento simbólico de exclusión y autoexclusión que se puede tomar como punto de partida para interpretar la posición del grabado en el campo artístico del siglo XX.

En efecto, la actuación corporativa de los grabadores y su uso de códigos y recetarios cuasi-secretos resulta, por una parte, un dato significativo para comprender este eventual alejamiento de la disciplina respecto del mapa principal de la producción simbólica. La idea de "defensa gremial" como profesión de fe -0, más bien, de fe ciega en el código estricto y cerrado de la disciplina- fue puesta en evidencia socarronamente por Luis Camnitzer desde el marco de una reflexión autocrítica sobre su praxis dentro de, en sus palabras, esta colonia de las artes:

Estaba usando una disciplina técnica para definirme, y conceptualmente, fue una equivocación. De alguna manera, había olvidado que tenía que buscar a mí mismo, y usar al grabado como una herramienta en esa búsqueda. En cambio, estaba limitando mi autodefinición a y dentro del grabado. Hago grabados, luego existo.

11 Citado en el catálogo Contribución al mayor conocimiento del grabado como obra de arte. Buenos Aires, Museo del Grabado, octubre de 1963.

12 Se puede mencionar en este sentido al paragone renacentista en el que, al comparar las artes entre sí -especialmente la pintura y la escultura- distintos autores evidenciaban las diferencias entre ellas. 
Desde aquella época, tengo todavía una adicción a las melodías aromáticas que emanan de tintas y solventes; miro como símbolos preciosos de status las manchas indelebles metidas bajo mis uñas; me erizo con dolor cuando alguien toma una hoja de papel sin permitir que adopte su curva catenaria, y creo que los grabadores que no limpian los bordes de sus chapas eventualmente reciben sus castigos en el infierno como corresponde. Lo cual significa que estoy, como es tan típico de los grabadores, atrapado dentro de un fundamentalismo técnico. (Camnitzer, 1997)13

Además de la exacerbación del parámetro técnico, otra particularidad que definió a la producción gráfica tradicional fue su recurrencia a la narratividad o figuración, debida muchas veces a su estrecha vinculación con el universo de la ilustración literaria o a la puesta en circulación de discursos sociales e imágenes de contenido político "militante". Frente a la toma de partido por la figuración, en la producción gráfica se dejaron de lado de forma casi excluyente las propuestas de la abstracción: en el caso argentino en particular -y en Latinoamérica en general- hasta bien entrados los años cincuenta no se produjeron grabados no figurativos. Tomando como punto de partida esta conjunción de las esferas formales y funcionales que le confirió al grabado algunos de estos rasgos constitutivos hasta la segunda posguerra, podemos formular aquí la siguiente hipótesis: esta "condición figurativa" lo apartó de uno de los grandes relatos que signó la producción artística del período, el modernismo.

El canon modernista desplazó el interés en el enfoque representacional y narrativo centrando su reflexión, contrariamente, en la valorización de la progresiva innovación y autorreferencialidad formal, como así también en la autonomización de la representación, desentendida de las circunstancias sociales. Según este lineamiento, se pusieron en primer plano las producciones donde el interés en los medios de la representación conformaba el objeto de la representación en sí: los elementos del arte como tema para el arte, a través de la búsqueda del objeto "puro" y autorreferido. Es sabido que una de las posiciones más conocidas en este sentido fue la sostenida por Clement Greenberg -elaborada a lo largo de varias décadas y cristalizada en su "Modernist painting"- donde remarcaba la importancia de los límites del arte y enfatizaba los rasgos específicos del medio. Desde su énfasis en la autonomía de la plástica (y de forma más amplia, de la cultura), el objetivo de Greenberg era desvincular al "Gran arte" de la cotidianeidad de la vida moderna.

Desde esta perspectiva, se sostiene aquí la interpretación de que algunas de las particularidades de la gráfica -figuración, narratividad, falta de unicidad- situaron al grabado como una de las producciones excluidas del canon del modernismo. Y si bien existen algunos ejemplos de grabados modernistas asociados a la producción de los "grandes nombres" del siglo XX que experimentaron con alguna de las técnicas del grabado -incluyendo a Pablo Picasso, Henri Matisse o Vassily 
Kandinsky- ${ }^{-14}$ cabe señalar que, desde el enfoque historiográfico o crítico, esa producción gráfica mantuvo un cariz diferencial o escindido del corpus "mayor" de los artistas: aparentemente, pinturas y estampas serían vistas como dos conjuntos cuya intersección se presenta de forma problemática o dificultosa, cuando no irresoluble.

Es evidente que las preferencias de los críticos y teóricos del arte -a través de sus reflexiones, selecciones y consagraciones- apuntaron a celebrar "el gran orden de la Pintura": el paradigma pictórico constituyó la orientación predominante dentro del campo artístico de la modernidad, y su normativización colocó en un lugar secundario a una cantidad significativa de prácticas y discursos que, contemporáneamente pero por fuera de este canon estético, produjeron sus propuestas.

En efecto, el modernismo no implicó un bloque monolítico: siguiendo la argumentación de Martin Jay, "el formalismo modernista celebrado por críticos como Greenberg olvidó [...] que el campo visual era un terreno en disputa en el cual la forma pura siempre encontraba la perturbadora oposición de su otro" (2003, p. 289). Aunque el formalismo pictórico resultó la tendencia hegemónica, no se lo puede entender exclusivamente desde un relato lineal, sin tomar en cuenta sus pliegues y fisuras. Tal es la interpretación de Marshall Berman cuando alega que el modernismo "contiene sus propias contradicciones internas y su dialéctica; que algunas formas del pensamiento y la visión modernistas se puedan petrificar en ortodoxias dogmáticas y volverse arcaicas; que otras formas de modernismo pueden quedar sumergidas durante generaciones" (1988, p. 172). En este sentido, si es posible incluir al impulso antiformalista o amorfismo como una "tradición subalterna" en la historia del modernismo, ¿se podría pensar al mantenimiento de la narratividad en el grabado como otra tendencia contrapuesta que -desde y a partir de un eventual plano subordinado- señala un lugar problemático de las tensiones de la propia modernidad?

Si por una parte se entiende que los grabadores se encerraron en la especificidad y "secretos" de sus prácticas técnicas desde un sentido gregario, también podemos pensar las causas por las que el canon modernista excluyó al grabado de su podio estético: ${ }^{15}$ una orientación que apuntaba a valorizar la progresiva autonomización de las formas y el discurso autorreferencial de la obra visual no podía tomar demasiado en cuenta una producción centrada en la representación narrativa. Así, si el modernismo sostenía una "apoteosis de la forma" (Jay, p. 275), el discurso de la gráfica presentaba una de sus posibles contracaras: el contenido, el tema, la referencia anecdótica, muchas veces política o social.

14 Al referir a sus grabados en madera incluidos en Klaenge (Munich, R. Piper et Cie., 1913), Kandinsky sostuvo que en sus xilografías "on retrouve les traces de mon développement du 'figuratif' à I' 'abstrait' ('concret' d'après ma terminologie)». "Mes gravures sur bois", $X X X^{e}$ siècle, a. 1, n. 3, juilletaoût-septembre 1938, p. 31.

15 Los textos de Clement Greenberg o Michael Fried, por ejemplo, raramente tratan sobre cuestiones ajenas al campo pictórico o, en menor medida, escultórico. 


\section{4.}

Para mediados del siglo XX, en los escritos sobre gráfica, la referencia quasi forzosa a los casos de Goya o Daumier, artistas paradigmáticos dentro del desarrollo del discurso comprometido y de denuncia social, detenía en un punto decimonónico este recorrido obligatorio. Estos mismos referentes fueron retomados hace pocos años por Eva Cockroft para aludir a la condición del medio gráfico como "el único acercamiento apropiado para la expresión artística de temas sociales" en la posguerra: "A causa de la dominancia en la pintura y la escultura del abstraccionismo, la mayor parte del arte latinoamericano de conciencia social expuesto en los Estados Unidos durante los años cincuenta era de artistas gráficos y no de pintores. En la tradición de Goya y Daumier, quienes habían establecido la legitimidad de imágenes enojadas, mordaces y satíricas para criticar asuntos políticos y sociales, el comentario social era [más] aceptable en las artes gráficas que en la pintura" (Cockroft, 1988, p. 206). En su lectura, que señala una implícita escisión entre el arte "autónomo" y "de compromiso", se plantea una división del trabajo artístico en el que el plano social -regresivo, en términos modernistascorrespondería a la esfera de producción del arte gráfico latinoamericano.

Efectivamente, esta es otra de las líneas sostenidas respecto del grabado: la tradición de la vinculación entre gráfica y política. A partir del potencial efecto movilizador que se puede desprender de la circulación seriada o plural de discursos artísticos de cuestionamiento y oposición, la idea del grabado como arte comprometido o de denuncia social constituye otro topos a partir del cual se ha entendido el lugar o la función de esta producción. Las imágenes de algunos gráficos alemanes como Käthe Kollwitz, Max Beckmann, Otto Dix o George Grosz, del flamenco Frans Masereel, o de los mexicanos José Guadalupe Posada o los miembros del Taller de Gráfica Popular conforman parte del imaginario respecto del uso del grabado como vehículo para la difusión del discurso social o comprometido. Esta línea de gráfica social fue seguida en el campo artístico argentino por la temprana obra de los Artistas del Pueblo, agrupación conformada por José Arato, Adolfo Bellocq, Guillermo Facio Hebequer, Agustín Riganelli y Abraham R. Vigo que desplegó sus actividades principalmente a lo largo de las décadas de 1910-1920.

Fue este paradigma gráfico el que resultó doblemente marginado -debido a su narratividad y a su contenido social explícito- por la mirada modernista. Pero si la disputa entre autorreferencialidad e ilustratividad apareció dominada por el primer término de la ecuación y el grabado quedó ubicado en una posición secundaria, podemos apuntar que los propios grabadores -situados conceptualmente más cerca de la corporación medieval que del régimen modernista- tampoco intentaron reivindicar su producción dentro de este terreno sino que construyeron un sistema de validación propio a partir, fundamentalmente, del virtuosismo en la realización técnica.

En la conjunción grabado-narratividad también operó otra tradición que se ligaba a la historia de la disciplina: su vinculación con la ilustración literaria. Esta relación también le confirió al grabado otros rasgos particulares, por ejemplo, la generalizada condición del pequeño formato de las estampas debido al destino de 
la imagen -libro o revista-, además de las limitaciones físicas de la platina de las prensas de impresión, o las dimensiones de las propias chapas-matrices. Otro rasgo característico en este sentido fue el predominio de la resolución monocromática: el blanco y negro constituyó la norma, y el uso del color la excepción a una regla implícita que circunscribía al grabado a este restringido binomio. ${ }^{16}$ La lectura ortodoxa remarcaba la significación del color como un elemento pictoricista tendiente a lo decorativo y extraño al mundo de lo gráfico. "El complemento de colores, no aportan sino un valor accesorio y convencional a los ya concretados en la plancha incisa, y que por otra parte, bajo el punto de vista ortodoxo de la técnica restan calidad y pureza al medio, invadiendo jurisdicciones que pertenecen a la pintura", sostenía la lectura purista de Víctor Rebuffo en 1948. ${ }^{17}$

Imágenes realizadas a partir de contrastes de planos o netos trazos lineales sobre fondos neutros que redundaron en una accesible síntesis visual, los grabados eran obras artísticas "de calidad" pero con un reducido costo económico por el material básico (tinta y papel), posibilitaban efectuar ediciones amplias impresas velozmente y tener un fácil transporte por el soporte de papel. Históricamente, la circulación de xilografías, aguafuertes y litografías dialogaron con las producciones escritas instalando el arte visual en el universo de la cultura letrada a través de un discurso figurativo de lectura comprensible. Aunque no es pertinente detenerse aquí en aspectos relacionados con el inicio del grabado, cabe mencionar que su primer "auge" corresponde al origen de la imprenta y la difusión del libro impreso en Occidente. Desde el siglo XIX, especialmente en Francia, la producción del peintre-graveur se vinculó muchas veces a fines ilustrativos, y la frecuente asociación entre artistas y escritores mantuvo al género del libro ilustrado como una sub-rama específica del campo gráfico. ${ }^{18}$

En el caso del libro ilustrado, la diferenciación entre la inclusión de impresiones directas de grabados o su reproducción señala una demarcación cualitativa entre una producción restringida que se vincularía a la "alta cultura" -el libro de edición limitada, de costo más elevado, destinado a un público reducido y especializado-, y el libro con reproducciones que, aunque se trata de "obras de arte" realizadas ad hoc, se vincula a la industria editorial masiva. Situados en la disyuntiva entre "alta" y "baja" cultura, el grabado permanece así dentro de la primera esfera, validado doblemente por su condición de creación artística y en su inserción en un objeto tan connotado para la cultura erudita como representa el libro. La relación grabado-ilustración forma parte de una de las orientaciones más extendidas dentro de las posibilidades de la disciplina, con gran cantidad de publicaciones -libros, revistas y periódicos- que otorgaron a los grabados un protagonismo central como medio de ilustración de los contenidos literarios o narrativos. En el caso argentino,

16 Se puede consignar, por ejemplo, que la American Color Print Society fue fundada en Philadelphia en 1939 con el objetivo de conformar un salón (National Color Print Exhibition) que aceptara de forma abierta los color prints, generalmente rechazados por los ortodoxos jurados.

17 Víctor Rebuffo, "El grabado", Buenos Aires, Ars, a. VII, n. 37, 1948, s/p.

18 Las vinculaciones entre grabado y texto escrito conforma uno de los ejes del tradicional texto de Ivins jr, (1975). 
podemos recordar que un referente central en relación con los usos de la estampa y su inclusión en proyectos artístico-culturales comprometidos fue el caso de la Editorial Claridad, en cuyos libros se incluyeron grabados e ilustraciones de los Artistas del Pueblo. Asimismo, desde fines de los años treinta o principios de los cuarenta, el grabado "de ilustración" también tuvo un lugar destacado en algunas de las editoriales llevadas adelante por exiliados españoles en Argentina, donde la gráfica de Luis Seoane tuvo un rol central.

También las revistas representaron una vía destacada para la circulación de imágenes gráficas; este soporte operó generalmente como medio de imbricación del rol de ilustración con la tradición del discurso gráfico-político. Por su resolución sintética y en blanco y negro, resultaban fácilmente editables, dando apoyo o anclaje visual a los planteos sostenidos desde los textos. A la vez, la inclusión en las publicaciones de la obra de los artistas grabadores posibilitó la circulación de imágenes en una mayor escala cuantitativa, potenciando su inherente multiplicidad.

En revistas de la década del treinta, como Contra. La revista de los francotiradores, Nervio. Crítica. Artes. Letras o Metrópolis. De los que escriben para decir algo, se reprodujeron gran cantidad de obras gráficas que, anticipando algunas veces su aparición en los círculos más estrictamente "artísticos", eran leídas como una contribución a la conformación de un imaginario político revolucionario. En esos momentos en los que las alianzas antifascistas cobraban gran impulso, los intercambios entre la obra de grabadores de distintos países contribuyeron a conformar una virtual trama simbólica de artistas. En Argentina, las imágenes de Víctor Rebuffo, Sergio Sergi o Pompeyo Audivert compartían el espacio de las publicaciones con obras de artistas europeos como Masereel, Kollwitz o Grosz, convertidos por los medios gráficos de izquierda en baluartes de la causa revolucionaria a través de sus manifiestos visuales. La circulación de imágenes gráficas de artistas europeos fue un fenómeno extendido durante el período: mientras que hacia fines de los años veinte también aparecen en la prensa uruguaya reproducciones de xilografías alemanas y nórdicas con connotaciones de crítica social (Peluffo Linari, 2003, pp. 17-19) estas obras también eran destacadas dentro de ciertos círculos de Brasil. En este sentido, es relevante recordar que el primer texto de Mário Pedrosa sobre artes plásticas refería a "las tendencias sociales del arte y Käthe Kollwitz" a partir de la influyente exposición de la grabadora en el Clube dos Artistas Modernos de São Paulo en 1933: si para el crítico, "a arte social hoje em dia não é, de fato, um passatempo delicioso: é uma arma", la grabadora alemana representaba al paradigma del artista social: "o destino da arte de Käthe Kollwitz não está, pois, na propia arte. Está socialmente no proletariado. É uma arte partidária e tendenciosa. Mas que assombrosa universalização!"19

Por esos mismos años, la producción gráfica de la alemana Kollwitz circulaba en Buenos Aires paralelamente a su publicación en las revistas. Justamente a 
raíz de una exposición de sus obras en la porteña galería Müller, en diciembre de 1933, el artista Demetrio Urruchúa sostenía que "esta notable grabadora ocupa, conjuntamente con Grosz y Masereel, un puesto de combate en la avanzada contemporánea del arte, con el espíritu y las fuerzas renovadoras de la causa revolucionaria". ${ }^{20}$ Fueron particularmente sus imágenes basadas en una iconografía tradicional de la historia del arte -con temas como Madre e hijo- o sus representaciones de las luchas obreras que se enmarcaban en una línea de protesta y denuncia por las difíciles condiciones de los trabajadores, las que impactaron especialmente en la obra del "artista del pueblo" Guillermo Facio Hebequer.

A la vez, si bien es indudable la vinculación del grabado "de ilustración" con el imaginario sociocultural asociado a los proyectos de las izquierdas, cabe señalar que éste no se circunscribió únicamente al mismo, sino que también fue un recurso para publicaciones culturales de distinto lineamiento ideológico. Baste recordar, en el contexto de los años veinte, el fuerte protagonismo de las xilografías y linóleos de Norah Borges en revistas como Prisma o Proa. Allí, la interdependencia entre los grabados de la artista con las poesías de su hermano Jorge Luis respondería al mismo tipo de alianza entre arte y literatura evidenciada en el caso de las revistas ultraístas españolas donde ambos habían participado (Artundo, 1988, p. 12). Este caso nos permite volver a poner en relieve las vinculaciones del grabado con la producción literaria, y a partir de esta relación, su circunscripción a los lineamientos discursivos de la figuración. Si la especial lectura de las vanguardias europeas en la obra gráfica de Norah Borges -con su mixtura de elementos cubistas, expresionistas y primitivistas- la vinculó a la escena de "lo nuevo" de los años veinte (Sarlo, 1988), su caso remarca, por otra parte, un aspecto de los límites del "deber ser" del grabado tal como se lo entendió de forma monolítica hasta mediados de siglo: aunque Norah proponía una renovación estética, se mantenía dentro de la resolución monocromática, figurativa y relacionada con el universo de la literatura.

Vinculado con la disciplina desde sus orígenes, el grabado figurativo empleado como "arte de ilustración" se mantuvo a lo largo del siglo XX como una tradición con continuidad. A la vez, la noción del grabado en tanto "arte social" también conformó uno de los lineamientos más firmemente establecidos sobre la funcionalidad de la estampa múltiple. Estos lugares que actuaron como referentes para entender esta producción -lugares asignados al grabado, lugares asumidos por los grabadorescomplejizaron su posición dentro el mapa de una producción artístico-visual dominada por el discurso modernista. Pero a su vez, la producción del grabado se mantuvo vigente como una obra problemática que sigue posibilitando formular preguntas sobre su cualidad híbrida.

20 D.U.C. [Demetrio Urruchúa], "Artes Plásticas", Nervio. Crítica. Artes. Letras, Buenos Aires, a. 3, n. 30, diciembre de 1933, p. 46. 


\section{GกIInBUT GBIIIÓกE}

\section{Referencias bibliográficas:}

ARANTES, Otília (org.). Mário Pedrosa, Política da Artes. São Paulo: Edusp, 1995.

ARTUNDO, Patricia. Norah Borges. Obra gráfica 1920-1930. Buenos Aires: Fondo Nacional de las Artes, 1994.

BAUDRILLARD, Jean. El sistema de los objetos. México: Siglo XXI, 1995. [10 ed 1969].

BENJAMIN, Walter. Discursos interrumpidos. Barcelona: Planeta, 1994.

. Libro de los Pasajes. Madrid: Akal, 2005.

BERMAN, Marshall. Todo lo sólido se desvanece en el aire. La experiencia de la modernidad. Madrid: Siglo XXI, 1988.

BUCK-MORSS, Susan. Dialéctica de la mirada. Walter Benjamin y el proyecto de los Pasajes. Madrid: Visor, 1995.

BURKE, Peter. Visto y no visto. El uso de la imagen como documento histórico. Barcelona: Crítica, 2001.

CAMNITZER, Luis. Sin título. In: Luis Camnitzer, José Guillermo Castillo, Liliana Porter- New York Graphic Workshop. Caracas: Museo de Bellas Artes, 1969.

. "Grabado. Una colonia de las artes plásticas". Catálogo Studio Camnitzer.

Buenos Aires: Museo Nacional del Grabado, 1997.

COCKROFT, Eva. "Los Estados Unidos y el arte latinoamericano de compromiso social: 1920-1970". In: AA.VV., El espíritu latinoamericano: arte y artistas en los Estados Unidos, 1920-1970. New York: Museo de Artes del Bronx- Harry N. Abrams, 1988.

DIDI-HUBERMAN, Georges. Lo que vemos, lo que nos mira. Buenos Aires: Manantial, 1997.

FREEDBERG, David. El poder de las imágenes. Madrid: Cátedra, 1992.

FRIED, Michael. Arte y objetualidad. Ensayos y reseñas. Madrid: La balsa de la Medusa-Antonio Machado libros, 2004.

IVINS JR, William M. (1975) Imagen impresa y conocimiento. Análisis de la imagen prefotográfica. Barcelona: Gustavo Gili, 1975.

JAY, Martin. "El modernismo y el abandono de la forma". In: Campos de fuerza. Entre la historia intelectual y la crítica cultural. Buenos Aires, Paidós, 2003.

KELLY, Mary. "Contribuciones a una re-visión de la crítica moderna". In: Brian Wallis (ed.), Arte después de la modernidad. Nuevos planteamientos en torno a la representación. Madrid: Akal, 2001.

MAINGUENEAU, Dominique. "L'énonciation philosophique comme institution discursive". In : Langages, n. 119, 1995.

O'BRIAN, John (ed.). Clement Greenberg, The Collected Essays and Criticism. 4 vol. Chicago y Londres: The University of Chicago Press, 1995.

PELUFFO LINARI, Gabriel. El grabado y la ilustración. Xilógrafos uruguayos entre 1920 y 1950. Montevideo: Museo Municipal de Bellas Artes Juan Manuel Blanes, 2003.

PONGE, Francis. "Matière et mémoire". In: L'atelier contemporain. Paris: Gallimard, 1977. 
SARLO, Beatriz. Una modernidad periférica. Buenos Aires 1920 y 1930. Buenos Aires: Nueva Visión, 1988.

VALERY, Paul. Piezas sobre arte. Madrid: Visor, 1999.

WILLIAMS, Raymond. Sociología de la cultura. Barcelona: Paidós, 1994 [1º reimpresión].

\begin{abstract}
:
The present work reviews some of the canonic approaches on the status of engravings as artistic production, both from the aspect of its graphic technique and its resort to narrative or to figuration, often connected to the universe of literary illustration or even the circulation of social images and discourses of a "militant" political content. The hypothesis here advanced is that both the narrative and the multiplicity of the engravings have generated a problem in relation to the modernist cannon; one sustains that the figurative condition - of illustration and/or social - of the graphic paradigm has situated the engraving as one of the excluded products from the modernist narrative, once the seclusion of engravers into technical virtuosity as the parameter for evaluation implied in its self-exclusion.
\end{abstract}

\title{
Key words:
}

Engraving, technique, multiple work, figuration, modernist narrative. 